\title{
molecules
}

ISSN 1420-3049

http://www.mdpi.org

Full Paper

\section{Synthesis, Antiviral and Antifungal Bioactivity of 2-Cyano-acrylate Derivatives Containing Phosphonyl Moieties}

\author{
Yin-Pu Lv, Xian-You Wang, Bao-An Song ${ }^{*}$, Song Yang, Kai Yan, Guang-Fang Xu, Pinaki S \\ Bhadury, Fang Liu, Lin-Hong Jin and De-Yu Hu
}

Center for Research and Development of Fine Chemicals, Guizhou University, Key Laboratory of Green Pesticide and Agricultural Bioengineering, Ministry of Education, Guiyang, 550025, P. R. China

* Author to whom correspondence should be addressed; E-mail: songbaoan22@yahoo.com, Tel.: (+86) 851 3620521, Fax: (+86) 8513622211

Received: 2 March 2007; in revised form 25 April 2007 / Accepted: 25 April 2007 / Published: 9 May 2007

\begin{abstract}
Alkyl 2-cyano-3-methylthio-3-phosphonylacrylates were synthesized by the reaction of alkyl 2-cyano-3,3-dimethylthioacrylates with dialkyl phosphites. The structures of the new compounds were characterized by elemental analyses, IR, ${ }^{1} \mathrm{H}-,{ }^{13} \mathrm{C}$ - and ${ }^{31} \mathrm{P}-\mathrm{NMR}$ spectral data. These compounds were tested in vitro against pathogenic fungi, namely, Fusarium graminearum, Cytospora mandshurica and Fusarium oxysporum. Amongst all compounds, $\mathbf{2 d}$ and $\mathbf{2 t}$ were found to be effective against the tested fungi at 50 $\mu \mathrm{g} / \mathrm{mL}$. A half-leaf method was used to determine the in vivo protective, inactivation and curative efficacies of the title products against tobacco mosaic virus (TMV). Title compounds $\mathbf{2 a}$ and $\mathbf{2 b}$ were found to possess good in vivo curative, protection and inactivation effects against TMV with inhibitory rates at $500 \mathrm{mg} / \mathrm{L}$ of $60.0,89.4$ and 56.5 and 64.2, 84.2 and $61.2 \%$, respectively. To the best of our knowledge, this is the first report on the antiviral and antifungal activity of alkyl 2-cyano-3-methylthio-3phosphonylacrylates.
\end{abstract}

Keywords: 2-Cyanoacrylate; phosphonyl moiety; antiviral activity; antifungal activity; synthesis. 


\section{Introduction}

Cyanoacrylates, a class of highly potent herbicidal compounds, are known to disrupt photosynthetic electron transportation at a common binding domain on the $32 \mathrm{kDa}$ polypeptide of the photosystem II (PSII) reaction center [1,2]. A large number of reports on the synthesis of cyanoacrylate derivatives exist due to their wide range of biological activities [3-6]. Some derivatives can serve not only as agrochemicals such as herbicides, insecticides, fungicides and plant virucides, but also as medicines such as antitumor agents. In our previous work, we designed and synthesized some chiral cyanoacrylates with antiviral activity by replacing the methylthio moiety of some 2-cyano-3-methylthio-3-substituted-phenylacrylates with $(R)$ - or $(S)$-1-phenylethylamine groups. The $(E)$ configuration of the reported chiral products was confirmed by X-ray single-crystal structure analysis. The bioassays showed that a chiral compound containing a 4-nitrophenyl moiety [(E)-ethyl 3[(S)-1-phenylethylamino]-3-(4-nitrophenylamino)-2-cyanoacrylate] exhibited good protection activity against TMV in vivo [7]. On the other hand, phosphonyl compounds, in general, have received wide attention in modern medicinal and pesticide chemistry. They are ideal for use in drug design due to their good bioactivity [8,9], low toxicity, and the ease of substitution with conventional heterocyclic ring groups [10-12]. In 2001 Chen et al. reported an efficient method for the synthesis of ethyl 2-cyano-3-methylthio-3-(diethoxyphosphonyl)acrylate under microwave irradiation conditions [13]. No reports on the fungitoxicity and antiviral activity of alkyl 2-cyano-3-methylthio-3-phosphonylacrylates have been published in the chemical or biological literature. In order to extend our research work on cyanoacrylates as antiviral agents and fungicides, we have designed and synthesized some novel cyanoacrylate derivatives 2a-2t containing phosphonyl moieties. The synthetic route is shown in Scheme 1. Diethyl phosphite or higher homologues were employed in the reaction due to their ease of preparation. The structures of $\mathbf{2}$ were established by well defined IR, NMR and elemental analysis. The results of bioassay revealed that some compounds of the above series have good anti-TMV and antifungal activity.

Scheme 1. Synthesis of compounds 2a-2t.

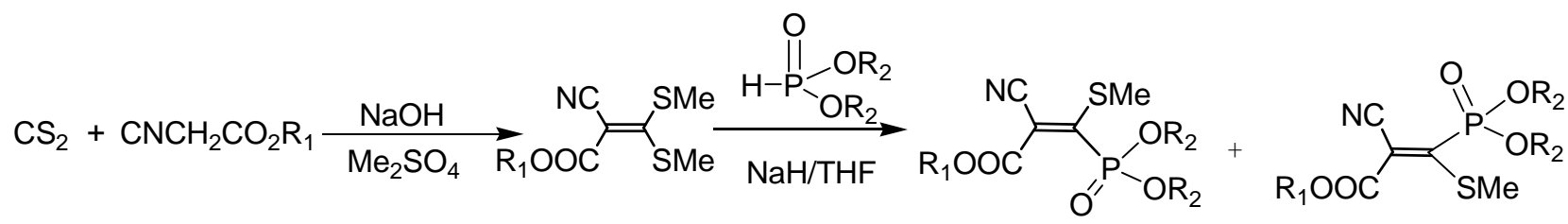

1

2

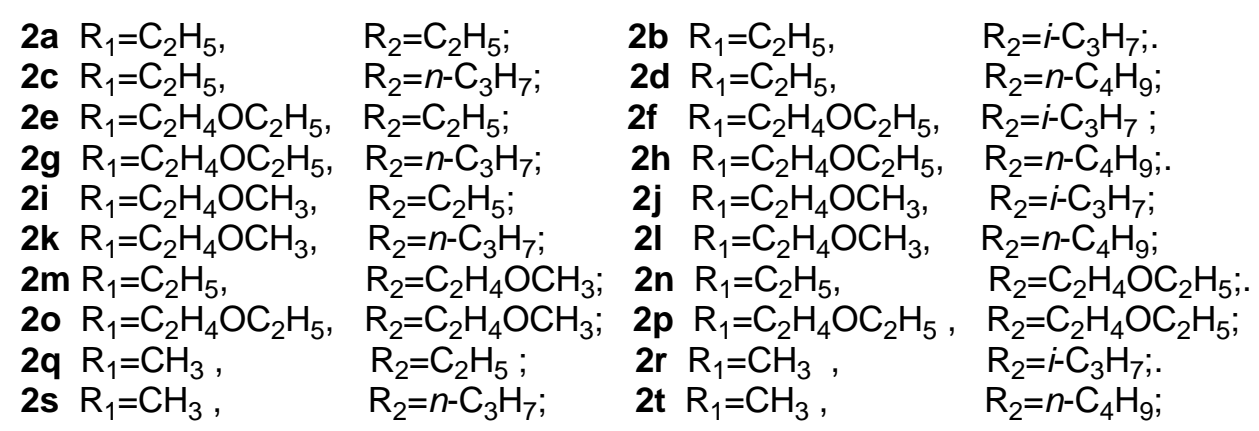




\section{Results and Discussion}

In order to optimize the reaction conditions for the syntheses of compounds $\mathbf{2 a - 2 t}$, the effects of various solvents, molar reagent ratios, reaction times and reaction temperatures on the reaction synthesis of $\mathbf{2} \mathbf{b}$ were examined. The results are summarized in Table 1 . Cyanoacrylate $\mathbf{2} \mathbf{b}$ was obtained from 1 in poor yield (Table 1, entries 1-3) in solvents such as DMF, acetone and $\mathrm{CH}_{3} \mathrm{CN}$, but when tetrahydrofuran (THF) was chosen as solvent, the yield of $\mathbf{2 b}$ increased from $11.2 \%$ to $55.0 \%$ (Table 1 , entries 1 , 4). Next we also examined the effect on the reaction of the molar ratios of the reactants. When the molar ratio of 2-cyano-3,3-(dimethylthio)- acrylate to $O$, $O$ '-di-i-propylphosphite to sodium hydride was increased from 1:1:1 to 1:3:1, 1:3:2, 1:3:3 and 1:3:4 eq, compound $2 \mathbf{b}$ was obtained in 0 , 12.0, 20.0, 55.0 and $49.5 \%$ yield, respectively (Table 1, entries 4-8). With regard to the reaction time 0 , 23.0 and 55.0 \% yields of $\mathbf{2 b}$ were noted after 4, 8 and 16 h, respectively (Table 1, entries 9, 10, 4). When the reaction time was prolonged further to 20 h, no significant improvement was obtained (56.0 $\%$, Table 1 , entry 11$)$, as compared to that seen after $16 \mathrm{~h}$ (55.0\%, Table 1, entry 4$)$. As for the reaction temperature, a lower yield was observed at lower temperature (Table 1, entry 12). It could also be seen that the yield was significantly lower when the reaction was performed at $40-45^{\circ} \mathrm{C}$ (Table 1 , entry 13), compared to that seen at room temperature (Table 1 , entry 4).

Table 1. Synthesis of $\mathbf{2 b}$ under different reaction conditions.

\begin{tabular}{cccccc}
\hline Entry & Solvent & Ratio $^{\boldsymbol{a}}$ & Time (h) & $\begin{array}{c}\text { Reaction } \\
\text { temperature }\end{array}$ & Yield (\%) ${ }^{\boldsymbol{b}}$ \\
\hline 1 & DMF & $1: 3: 3$ & 16 & r.t & 11.2 \\
2 & acetone & $1: 3: 3$ & 16 & r.t & 19.0 \\
3 & $\mathrm{CH}_{3} \mathrm{CN}$ & $1: 3: 3$ & 16 & r.t & 34.9 \\
4 & THF & $1: 3: 3$ & 16 & r.t & 55.0 \\
5 & THF & $1: 3: 1$ & 16 & r.t & 12.0 \\
6 & THF & $1: 3: 2$ & 16 & r.t & 20.0 \\
7 & THF & $1: 1: 1$ & 16 & r.t & 0 \\
8 & THF & $1: 3: 4$ & 16 & r.t & 49.5 \\
9 & THF & $1: 3: 3$ & 4 & r.t & 0 \\
10 & THF & $1: 3: 3$ & 8 & r.t & 23.0 \\
11 & THF & $1: 3: 3$ & 20 & r.t & 56.0 \\
12 & THF & $1: 3: 3$ & 16 & $0-5^{\circ} \mathrm{C}$ & 23.0 \\
13 & THF & $1: 3: 3$ & 16 & $40-45^{\circ} \mathrm{C}$ & 13.0 \\
\hline$a$ & Ratio of 2-cyano-3,3-dimethylthioacrylate:O,O'-di-i-propylphosphite:sodium hydride \\
${ }^{b}$ & Isolated yield based on 2-cyano-3,3-dimethylthioacrylate & &
\end{tabular}

Antifungal Bioassay: Inhibitory effects of cyanoacrylate derivatives on phytopathogenic fungi

The three fungi used in the fungicidal bioassay, Fusarium graminearum, Cytospora mandshurica and Fusarium oxysporum, were tested by the poison plate technique. The results of preliminary bioassays were compared with that of a commercial agricultural fungicide, hymexazol. As indicated in 
Table 2, the new compounds $\mathbf{2 d}$ and $\mathbf{2 t}$ exhibited promising antifungal activity, inhibiting growth of $F$. graminearum at 64.5 and $49.7 \%$, C. mandshurica at 60.4 and $51.3 \%$ and F. oxysporum at 65.0 and $41.1 \%$, respectively, which is a little lower than that of hymexazole (73.2 \% against F. graminearum, $58.9 \%$ against C. mandshurica, and $65.5 \%$ against $F$. oxysporum at $50 \mu \mathrm{g} / \mathrm{mL}$ ). Marked loss of activity was observed with other compounds such as $\mathbf{2 a - 2 c}$ and $\mathbf{2 e - 2 s .}$

Table 2. Inhibition effects of the title compounds on fungi.

\begin{tabular}{|c|c|c|c|c|}
\hline \multirow[b]{2}{*}{ Compd. } & \multirow{2}{*}{$\begin{array}{c}\text { Conc. } \\
(\mu \mathrm{g} / \mathrm{mL})\end{array}$} & \multicolumn{3}{|c|}{ Inhibition rate $(\%)$} \\
\hline & & $\begin{array}{c}\text { Fusarium } \\
\text { graminearum }\end{array}$ & $\begin{array}{c}\text { Cytospora } \\
\text { mandshurica }\end{array}$ & $\begin{array}{c}\text { Fusarium } \\
\text { oxysporum }\end{array}$ \\
\hline \multirow{2}{*}{$2 a$} & 50 & $11.14 \pm 0.21$ & $11.00 \pm 0.25$ & $18.21 \pm 0.11$ \\
\hline & 500 & $37.30 \pm 0.56$ & $24.00 \pm 0.77$ & $26.03 \pm 0.99$ \\
\hline \multirow{2}{*}{$2 \mathbf{b}$} & 50 & $4.94 \pm 0.49$ & $1.34 \pm 0.65$ & $8.08 \pm 0.98$ \\
\hline & 500 & $31.40 \pm 0.78$ & $35.03 \pm 0.84$ & $36.83 \pm 1.24$ \\
\hline \multirow{2}{*}{ 2c } & 50 & $8.31 \pm 0.57$ & $13.10 \pm 0.78$ & $13.47 \pm 1.24$ \\
\hline & 500 & $37.10 \pm 1.08$ & $31.82 \pm 1.45$ & $41.02 \pm 1.30$ \\
\hline \multirow{2}{*}{ 2d } & 50 & $64.50 \pm 0.40$ & $60.43 \pm 0.63$ & $65.03 \pm 1.22$ \\
\hline & 500 & $93.30 \pm 4.28$ & $90.59 \pm 1.59$ & $92.75 \pm 2.52$ \\
\hline \multirow{2}{*}{$2 e$} & 50 & $22.04 \pm 0.90$ & $32.01 \pm 0.78$ & $26.71 \pm 0.90$ \\
\hline & 500 & $41.44 \pm 1.21$ & $36.77 \pm 1.45$ & $32.13 \pm 1.09$ \\
\hline \multirow{2}{*}{$2 f$} & 50 & $35.22 \pm 1.78$ & $41.09 \pm 3.21$ & $46.11 \pm 3.34$ \\
\hline & 500 & $55.64 \pm 3.01$ & $66.09 \pm 2.55$ & $68.9 \pm 1.19$ \\
\hline \multirow{2}{*}{$2 g$} & 50 & $7.79 \pm 0.57$ & $-0.80 \pm 0.72$ & $6.29 \pm 0.97$ \\
\hline & 500 & $40.0 \pm 2.15$ & $49.47 \pm 1.01$ & $48.80 \pm 1.33$ \\
\hline \multirow{2}{*}{$2 h$} & 50 & $4.68 \pm 0.56$ & $-3.21 \pm 0.85$ & $5.99 \pm 0.87$ \\
\hline & 500 & $25.41 \pm 0.73$ & $23.26 \pm 0.84$ & $36.53 \pm 1.27$ \\
\hline \multirow{2}{*}{$2 \mathbf{i}$} & 50 & $5.45 \pm 0.73$ & $-2.67 \pm 0.67$ & $1.20 \pm 0.89$ \\
\hline & 500 & $16.3 \pm 0.64$ & $8.29 \pm 0.76$ & $20.06 \pm 0.97$ \\
\hline \multirow{2}{*}{$2 \mathbf{j}$} & 50 & $0.97 \pm 0.11$ & $11.27 \pm 0.45$ & $9.99 \pm 0.22$ \\
\hline & 500 & $20.00 \pm 0.21$ & $26.78 \pm 0.44$ & $30.99 \pm 1.09$ \\
\hline \multirow{2}{*}{$2 \mathbf{k}$} & 50 & $10.09 \pm 0.76$ & $32.20 \pm 0.55$ & $19.39 \pm 0.44$ \\
\hline & 500 & $31.03 \pm 0.90$ & $36.38 \pm 1.32$ & $40.22 \pm 1.45$ \\
\hline \multirow{2}{*}{21} & 50 & $21.08 \pm 0.98$ & $30.07 \pm 0.67$ & $12.11 \pm 1.02$ \\
\hline & 500 & $34.01 \pm 1.67$ & $29.51 \pm 1.02$ & $32.00 \pm 0.69$ \\
\hline \multirow{2}{*}{$2 m$} & 50 & $3.93 \pm 0.22$ & $14.23 \pm 0.51$ & $23.09 \pm 0.88$ \\
\hline & 500 & $27.31 \pm 0.99$ & $16.08 \pm 0.55$ & $41.90 \pm 2.01$ \\
\hline \multirow{2}{*}{$2 n$} & 50 & $12.22 \pm 1.01$ & $9.97 \pm 0.88$ & $11.91 \pm 0.42$ \\
\hline & 500 & $24.04 \pm 0.62$ & $36.09 \pm 0.55$ & $35.69 \pm 1.90$ \\
\hline \multirow{2}{*}{20} & 50 & $3.75 \pm 0.52$ & $10.61 \pm 0.69$ & $4.01 \pm 0.55$ \\
\hline & 500 & $21.08 \pm 0.65$ & $48.28 \pm 0.96$ & $29.07 \pm 0.65$ \\
\hline \multirow{2}{*}{$2 p$} & 50 & $4.45 \pm 0.55$ & $24.93 \pm 0.76$ & $6.52 \pm 0.56$ \\
\hline & 500 & $28.10 \pm 0.69$ & $47.21 \pm 0.95$ & $35.59 \pm 0.69$ \\
\hline
\end{tabular}


Table 2. Cont.

\begin{tabular}{crccc}
\hline $\mathbf{2 q}$ & 50 & $7.03 \pm 0.60$ & $15.38 \pm 0.61$ & $3.26 \pm 0.44$ \\
& 500 & $42.15 \pm 0.79$ & $57.82 \pm 1.11$ & $33.58 \pm 0.68$ \\
$\mathbf{2}$ & 50 & $11.71 \pm 0.96$ & $23.87 \pm 0.75$ & $9.52 \pm 0.57$ \\
& 500 & $44.03 \pm 0.81$ & $64.72 \pm 1.26$ & $52.13 \pm 0.84$ \\
$2 \mathbf{2}$ & 50 & $9.84 \pm 0.61$ & $35.01 \pm 0.72$ & $13.53 \pm 0.48$ \\
& 500 & $53.40 \pm 0.92$ & $65.78 \pm 1.29$ & $56.64 \pm 0.90$ \\
$2 \mathbf{2 t}$ & 50 & $49.67 \pm 0.65$ & $51.30 \pm 0.70$ & $41.05 \pm 0.51$ \\
& 500 & $81.97 \pm 2.91$ & $75.33 \pm 1.71$ & $69.42 \pm 1.23$ \\
Hymexazol $^{a}$ & 50 & $73.2 \pm 1.41$ & $58.89 \pm 1.16$ & $65.51 \pm 1.76$ \\
DMSO $^{\boldsymbol{b}}$ & 500 & $100 \pm 0.66$ & $95.33 \pm 1.87$ & $93.18 \pm 3.76$ \\
\end{tabular}

${ }^{a}$ reference compound; ${ }^{b}$ control.

Figure 1 shows the inhibition of mycelial growth of isolated hypha of $F$. oxysporum by compound 2d at different concentrations $(100,50,25,10$, and $1 \mu \mathrm{g} / \mathrm{mL})$ as compared to control, when tested in vitro. Almost complete inhibition of mycelial growth was observed at 100 and $50 \mu \mathrm{g} / \mathrm{mL}$ concentrations as compared to control (full growth).

Figure 1. Effect of various concentrations of $\mathbf{2 d}$ on the growth of isolated hypha of $F$. oxysporum (100, 50, 25, 5 and $1 \mu \mathrm{g} / \mathrm{mL})$.

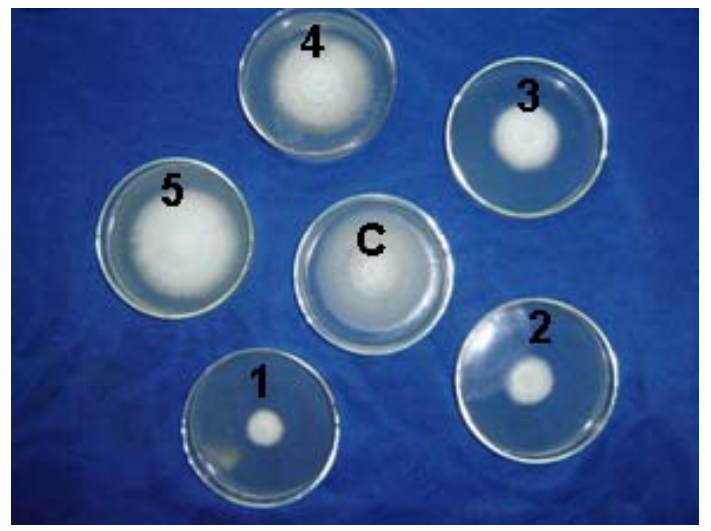

Key $(\mu \mathrm{g} / \mathrm{mL}): 1,100 ; 2,50 ; 3,25 ; 4,5 ; 5,1$; and C, control.

\section{Micro-observation results}

Microphotography of the hyphal morphology of F. oxysporum treated with $100 \mu \mathrm{g} / \mathrm{mL}$ of $\mathbf{2 d}$ (Figure 2) showed a series of changes, i.e. the cell of the hyphal divarication increased, hyphal knots appeared, and hypha bulged partially, compared with control. 
Figure 2. Microphotograph $(800 \times)$ of hyphal morphology of F. oxysporum treated with 2d.

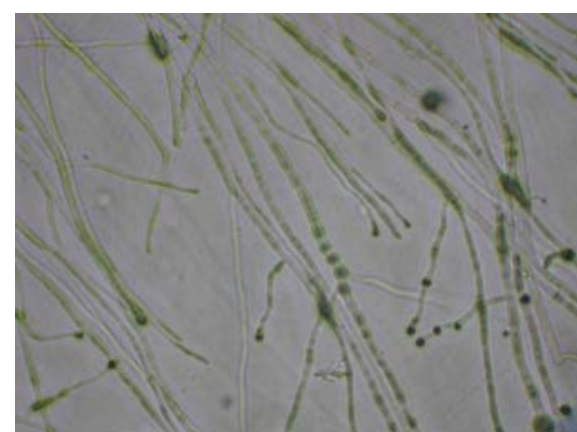

ck

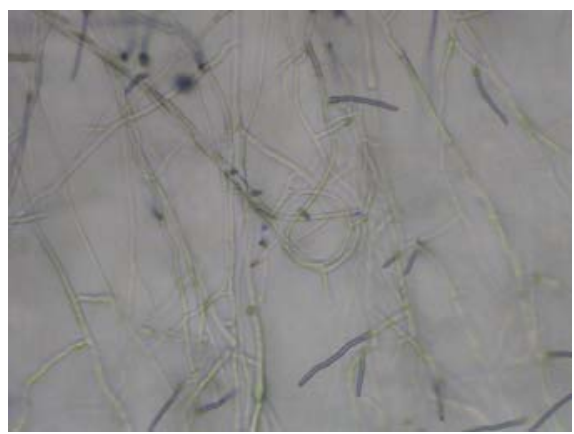

2d

Preliminary antiviral activity assay

The results of the in vivo bioassay against TMV are given in Table 3. Ningnanmycin was used as reference antiviral agent. The data provided in the table indicate that the introduction of dialkylphosphonyl moieties in cyanoacrylates might improve their protective activities. The title compounds 2a-2t showed protection rates of 40.8-61.2 \%. When $\mathrm{R}_{1}$ and $\mathrm{R}_{2}$ are Et, the resulting compound 2a displayed a lower protective activity (56.5\%) than that of the reference compound (62.6 \%). The highest protective activity was achieved when $\mathrm{R}_{1}$ is $E t$ and $\mathrm{R}_{2}$ is $i$ - $\operatorname{Pr}$ (compound $\mathbf{2 b}$ ). A protective rate of $61.2 \%$, equivalent to ningnanmycin, against TMV at $500 \mu \mathrm{g} / \mathrm{mL}$ was recorded in this case. From the data in Table 3, it may be observed that the title compounds $\mathbf{2 a - 2 t}$ possess significant potential inactivation bioactivities, with values of 89.4, 84.7, 76.3, 80.3, 74.2, 79.6, 73.8, 70.8, 80.0, 77.9, 79.0, 78.2, 81.2, 80.2, 68.9, 67.3, 60.0, 70.0, 80.2 and $61.0 \%$ at $500 \mu \mathrm{g} / \mathrm{mL}$, respectively. Among these compounds, $\mathbf{2 a}\left(\mathrm{R}_{1}\right.$ and $\mathrm{R}_{2}$ are $\left.\mathrm{Et}\right)$ is much more active against TMV than the other ones, with an inactivation rate of $89.4 \%$, equivalent to ningnanmycin (92.6 \%) against TMV at $500 \mu \mathrm{g} / \mathrm{mL}$. The data also indicate that a change in the substituent might also affect the curative activity of the title compounds 2a-2t. Compound $\mathbf{2 a}\left(\mathrm{R}_{1}\right.$ and $\mathrm{R}_{2}$ are $\mathrm{Et}$ ) and compound $\mathbf{2 b}$ could cure TMV up to $60.0 \%$ and $64.2 \%$ at $500 \mu \mathrm{g} / \mathrm{mL}$. The other compounds have a relatively lower curative activity than 2a and 2b.

Table 3. The Protective, inactivation and curative effects of the new compounds against TMV in vivo.

\begin{tabular}{ccccc}
\hline Agents & $\begin{array}{c}\text { Concentration } \\
(\mathrm{mg} / \mathrm{L})\end{array}$ & $\begin{array}{c}\text { Protective } \\
\text { Effect (\%) }\end{array}$ & $\begin{array}{c}\text { Inactivation } \\
\text { Effect (\%) }\end{array}$ & $\begin{array}{c}\text { Curative } \\
\text { Effect(\%) }\end{array}$ \\
\hline 2a & 500 & $56.5^{*} \pm 1.4$ & $89.4^{* *} \pm 2.0$ & $60.0^{*} \pm 0.9$ \\
$\mathbf{2 b}$ & 500 & $61.2^{*} \pm 3.2$ & $84.7^{* *} \pm 1.0$ & $64.2^{*} \pm 1.9$ \\
$\mathbf{2 c}$ & 500 & $53.0^{*} \pm 1.8$ & $76.3^{*} \pm 2.4$ & $45.8^{*} \pm 1.0$ \\
$\mathbf{2 d}$ & 500 & $53.4^{*} \pm 0.7$ & $80.3^{* *} \pm 3.4$ & $41.2^{*} \pm 2.1$ \\
$\mathbf{2 e}$ & 500 & $45.0^{*} \pm 1.1$ & $74.2^{*} \pm 3.4$ & $54.7^{*} \pm 2.2$ \\
$\mathbf{2 f}$ & 500 & $47.9^{*} \pm 1.7$ & $79.6^{* *} \pm 1.6$ & $28.4 \pm 4.4$ \\
$\mathbf{2 g}$ & 500 & $40.8^{*} \pm 5.4$ & $73.8^{*} \pm 3.0$ & $41.8^{*} \pm 5.5$ \\
$\mathbf{2 h}$ & 500 & $46.5^{*} \pm 2.3$ & $70.8^{*} \pm 1.4$ & $31.4^{*} \pm 1.7$ \\
\hline
\end{tabular}


Table 3. Cont.

\begin{tabular}{|c|c|c|c|c|}
\hline $2 \mathbf{i}$ & 500 & $50.1 * \pm 3.0$ & $80.0 * * \pm 2.0$ & $36.6^{*} \pm 4.4$ \\
\hline $2 \mathbf{j}$ & 500 & $43.2 * \pm 5.4$ & $77.9 * \pm 0.9$ & $42.1 * \pm 3.8$ \\
\hline $2 \mathbf{k}$ & 500 & $45.7 * \pm 1.9$ & $79.0 * \pm 0.7$ & $44.3^{*} \pm 6.4$ \\
\hline 21 & 500 & $51.2 * \pm 1.1$ & $78.2 * \pm 0.9$ & $42.0 * \pm 1.5$ \\
\hline $2 \mathrm{~m}$ & 500 & $50.0 * \pm 2.0$ & $81.2 * \pm 1.6$ & $50.0 * \pm 1.0$ \\
\hline $2 n$ & 500 & $49.7 \pm 8.0$ & $80.2^{* *} \pm 1.2$ & $51.2 * \pm 1.0$ \\
\hline 20 & 500 & $48.9 * \pm 0.9$ & $68.9 * \pm 5.3$ & $33.3^{*} \pm 4.9$ \\
\hline $2 p$ & 500 & $47.6 * \pm 1.0$ & $67.3 * \pm 2.4$ & $33.3 \pm 8.9$ \\
\hline $2 q$ & 500 & $45.6 * \pm 0.4$ & $60.0 * \pm 3.1$ & $10.9 \pm 6.0$ \\
\hline $2 \mathbf{r}$ & 500 & $50.9 * \pm 1.1$ & $70.0 * \pm 1.9$ & $36.7 * \pm 6.7$ \\
\hline $2 s$ & 500 & $51.2 * \pm 0.9$ & $80.2^{* *} \pm 2.0$ & $41.4^{*} \pm 9.9$ \\
\hline $2 t$ & 500 & $46.6 * \pm 5.5$ & $61.0 * \pm 5.1$ & $24.1 \pm 8.7$ \\
\hline Ningnamycin & 500 & $62.6 * \pm 2.1$ & $92.6^{* *} \pm 1.0$ & $53.9 * \pm 2.3$ \\
\hline
\end{tabular}

All results are expressed as mean $\pm \mathrm{SD} ; n=3$ for all groups; $* P<0.05, * * P<0.01$.

\section{Conclusions}

A series of novel cyanoacrylate derivatives 2a-2t containing phosphonyl moieties were synthesized by treatment of alkyl 2-cyano-3,3-dimethylthioacrylates and dialkyl phosphites with $\mathrm{NaH}$ in THF solvent. This method is easy and gields the title compounds in moderate yields. The structures were verified by spectroscopic data. In the antifungal bioassay, the title compounds $\mathbf{2} \mathbf{d}$ and $\mathbf{2} \mathbf{t}$ were found to possess the highest activity against three kinds of fungi in vitro. The bioassay results showed that these title compounds exhibited moderate to good anti-TMV bioactivity. Title compounds $\mathbf{2 a}$ and $\mathbf{2 b}$ showed better biological activity than their structurally related analogues $\mathbf{2 c - 2 t}$.

\section{Acknowledgements}

The authors wish to thank the National Key Project for Basic Research (Grant No. 2003CB114404, 2005CCA01500) and Key Technologies R\&D Program (Grant No. 2006BAE01A02-5) and the National Natural Science Foundation of China (Grant No. 20672024) for their financial support.

\section{Experimental}

\section{General}

The melting points of the products were determined on an XT-4 binocular microscope (Beijing Tech Instrument Co., P.R. China) and were not corrected. The IR spectra were recorded on a Bruker VECTOR 22 spectrometer in $\mathrm{KBr}$ disks. ${ }^{1} \mathrm{H}-,{ }^{13} \mathrm{C}$ - and ${ }^{31} \mathrm{P}-\mathrm{NMR}$ spectra (solvent $\mathrm{CDCl}_{3}$ ) were recorded on a JEOL-ECX 500 NMR spectrometer at room temperature using TMS as an internal standard. Elemental analysis was performed on an Elementar Vario-III CHN analyzer. Analytical TLC was performed on silica gel GF254. Column chromatographic purification was carried out using silica gel. All reagents either belonged to analytical reagent grade or were chemically pure. THF was dried, 
deoxygenated and redistilled before use. Dialkyl phosphites and alkyl 2-cyano-3,3-(dimethylthio)acrylates were prepared according to literature methods [14, 15].

General procedure for the preparation of title compounds $\mathbf{2 a - 2 t .}$

A dry $100 \mathrm{~mL}$ round-bottom flask equipped with a magnetic stirrer and nitrogen inlet was charged with sodium hydride $(0.66 \mathrm{~g}, 55 \%, 15.2 \mathrm{mmol})$ in $\mathrm{THF}(15 \mathrm{~mL})$ at $0 \sim 5{ }^{\circ} \mathrm{C}$. Dialkyl phosphite $(15.2$ mmol) was than slowly added through a dropping funnel into the resulting solution over a period of 30 min. Alkyl 2-cyano-3,3-(dimethylthio)acrylate $(5.0 \mathrm{mmol})$ in THF $(20 \mathrm{~mL})$ was then slowly added to the above solution. The mixture was stirred for $16 \mathrm{~h}$ at room temperature. After removal of the solvent under vacuum, the residue was dissolved in ice-cold water $(40 \mathrm{~mL})$ and acidified with dilute hydrochloric acid (10\%), extracted with ethyl acetate $(3 \times 20 \mathrm{~mL})$ and the combined organic layer was dried over anhydrous magnesium sulfate, filtered, and concentrated. The residue was subjected to column chromatography using a mixture of petroleum ether and ethyl acetate (4:1) as eluent to give the title compounds $\mathbf{2 a}-\mathbf{2 t}$.

\section{Yields and product characterization}

Ethyl 2-cyano-3-methylthio-3-(diethoxyphosphonyl)acrylate (2a): yellow liquid; yield $52.0 \%$; ${ }^{1} \mathrm{H}$ NMR $\delta: 1.37 \sim 1.45\left(\mathrm{~m}, 9 \mathrm{H}\right.$, ester $\mathrm{CH}_{3}+2 \times$ phosphonyl $\left.\mathrm{CH}_{3}\right), 2.76\left(\mathrm{~d}, J=6.8 \mathrm{~Hz}, 3 \mathrm{H}, \mathrm{SCH}_{3}\right)$, 4.32 4.35 (m, 6H, ester $\mathrm{CH}_{2}+2 \times$ phosphonyl $\mathrm{CH}_{2}$ ); ${ }^{13} \mathrm{C}-\mathrm{NMR} \delta: 14.1$ (ester $\mathrm{CH}_{3}$ ), 16.2 (2×phosphonyl $\left.\mathrm{CH}_{3}\right), 19.4\left(\mathrm{SCH}_{3}\right), 62.7$ (ester $\left.\mathrm{OCH}_{2}\right), 64.5\left(2 \times\right.$ phosphonyl $\left.\mathrm{CH}_{2}\right), 106.2(\mathrm{C}=\mathrm{C} \mathrm{C}-2)$, 114.5 (CN), 162.1 (C=C C-3), 165.7 (C=O); ${ }^{31} \mathrm{P}-\mathrm{NMR} \delta$ : 5.1; IR $v: 2983,2214,1745,1251,1018 \mathrm{~cm}^{-1}$; Anal. Calcd. for $\mathrm{C}_{11} \mathrm{H}_{18} \mathrm{NO}_{5} \mathrm{PS}$ (307.5): C, 42.93; H, 5.58; N, 4.55. Found: C, 42.99; H, 5.90; N, 4.56.

Ethyl 2-cyano-3-methylthio-3-(di-i-propoxyphosphonyl)acrylate (2b): yellow liquid; yield 55.0\%; ${ }^{1} \mathrm{H}$ NMR $\delta$ : $1.36 \sim 1.38\left(\mathrm{~m}, 15 \mathrm{H}, 4 \times\right.$ phosphonyl $\mathrm{CH}_{3}+$ ester $\left.\mathrm{CH}_{3}\right), 2.73\left(\mathrm{~d}, J=6.9 \mathrm{~Hz}, 3 \mathrm{H}, \mathrm{SCH}_{3}\right), 4.33$ (q, $J=7.2 \mathrm{~Hz}, 2 \mathrm{H}$, ester $\mathrm{CH}_{2}$ ), 4.82 4.89 (m, 2H, $2 \times$ phosphonyl $\mathrm{CH}$ ); ${ }^{13} \mathrm{C}-\mathrm{NMR} \delta: 14.1$ (ester $\mathrm{CH}_{3}$ ), $19.4\left(\mathrm{SCH}_{3}\right), 23.9\left(4 \times\right.$ phosphonyl $\left.\mathrm{CH}_{3}\right), 63.1\left(\right.$ ester $\left.\mathrm{OCH}_{2}\right), 64.5\left(2 \times\right.$ phosphonyl $\left.\mathrm{CH}_{2}\right), 74.2(2 \times$ phosphonyl CH), 106.9 (C=C C-2), 114.7 (CN), 162.1 (C=C C-3), $165.3(\mathrm{C}=\mathrm{O})$; ${ }^{31} \mathrm{P}-\mathrm{NMR} \delta$ : 3.5; IR $v$ : 2980, 2212, 1718, 1504, 1246, $987 \mathrm{~cm}^{-1}$; Anal. Calcd. for $\mathrm{C}_{13} \mathrm{H}_{22} \mathrm{NO}_{5} \mathrm{PS}$ (335.1): C, 46.55; H, 6.56; N, 4.18. Found: C, 46.56; H, 6.61; N, 4.10.

Ethyl 2-cyano-3-methylthio-3-(di-n-propoxyphosphonyl)acrylate (2c): yellow liquid; yield 50.0\%; ${ }^{1} \mathrm{H}$ NMR $\delta$ : 0.98 1.02 (m, 6H, $2 \times$ phosphonyl $\left.\mathrm{CH}_{3}\right), 1.37\left(\mathrm{t}, J=7.5 \mathrm{~Hz}, 3 \mathrm{H}\right.$, ester $\left.\mathrm{CH}_{3}\right), 1.73 \sim 1.75$ (m, $4 \mathrm{H}, 2 \times$ phosphonyl $\mathrm{CH}_{2}$ ), 2.75 (d, $\left.J=6.9 \mathrm{~Hz}, 3 \mathrm{H}, \mathrm{SCH}_{3}\right), 4.09 \sim 4.19\left(\mathrm{~m}, 4 \mathrm{H}, 2 \times\right.$ phosphonyl $\mathrm{CH}_{2}$ ), 4.33 (q, $J=7.1 \mathrm{~Hz}, 2 \mathrm{H}$, ester $\mathrm{CH}_{2}$ ); ${ }^{13} \mathrm{C}-\mathrm{NMR} \delta: 10.0$ (2 $\times$ phosphonyl $\mathrm{CH}_{3}$ ), 14.1 (ester $\left.\mathrm{CH}_{3}\right), 19.5$ $\left(\mathrm{SCH}_{3}\right), 23.7$ (2 $\times$ phosphonyl $\left.\mathrm{CH}_{2}\right), 63.3\left(\right.$ ester $\left.\mathrm{OCH}_{2}\right), 69.8$ (2 $\times$ phosphonyl $\left.\mathrm{CH}_{2}\right), 106.5(\mathrm{C}=\mathrm{C} \mathrm{C}-2)$, 114.6 (CN), 162.1 (C=C C-3), $165.5(\mathrm{C}=\mathrm{O}) ;{ }^{31} \mathrm{P}-\mathrm{NMR} \delta:$ 5.9; IR v: 2970, 2214, 1735, 1463, 1251, $1006 \mathrm{~cm}^{-1}$; Anal. Calcd. for $\mathrm{C}_{13} \mathrm{H}_{22} \mathrm{NO}_{5} \mathrm{PS}$ (335.1): C, 46.55; H, 6.56; N, 4.18. Found: C, 46.56; $\mathrm{H}$, $6.61 ; \mathrm{N}, 4.18$. 
Ethyl 2-cyano-3-methylthio-3-(di-n-butoxyphosphonyl)acrylate (2d): yellow liquid; yield $45.6 \%$; ${ }^{1} \mathrm{H}$ NMR $\delta$ : 0.94 0.97 (m, 6H, $2 \times$ phosphonyl $\mathrm{CH}_{3}$ ), 1.37 (t, $J=7.2 \mathrm{~Hz}, 3 \mathrm{H}$, ester $\left.\mathrm{CH}_{3}\right), 1.39 \sim 1.46$ (m, 4H, $2 \times$ phosphonyl $\left.\mathrm{CH}_{2}\right), 1.73 \sim 1.77\left(\mathrm{~m}, 4 \mathrm{H}, 2 \times\right.$ phosphonyl $\left.\mathrm{CH}_{2}\right), 2.74\left(\mathrm{~d}, J=6.9 \mathrm{~Hz}, 3 \mathrm{H}, \mathrm{SCH}_{3}\right)$, 4.23 4.34 (m, 6H, $2 \times$ phosphonyl $\mathrm{CH}_{2}+$ ester $\left.\mathrm{CH}_{2}\right)$; ${ }^{13} \mathrm{C}-\mathrm{NMR} \delta$ : $13.5\left(2 \times\right.$ phosphonyl $\left.\mathrm{CH}_{3}\right), 13.6$ (ester $\left.\mathrm{CH}_{3}\right), 18.7\left(2 \times\right.$ phosphonyl $\left.\mathrm{CH}_{2}\right), 18.8\left(\mathrm{SCH}_{3}\right), 32.3\left(2 \times\right.$ phosphonyl $\left.\mathrm{CH}_{2}\right), 62.8\left(\right.$ ester $\left.\mathrm{CH}_{2}\right)$, $68.0\left(2 \times\right.$ phosphonyl CH), 106.4 (C=C C-2), $114.5(\mathrm{CN}), 162.1(\mathrm{C}=\mathrm{C} \mathrm{C}-3), 165.6(\mathrm{C}=\mathrm{O}) ;{ }^{31} \mathrm{P}-\mathrm{NMR} \delta$ : 5.5; IR v: 2960, 2214, 1735, 1465, 1259, $1028 \mathrm{~cm}^{-1}$; Anal. Calcd. for $\mathrm{C}_{15} \mathrm{H}_{26} \mathrm{NO}_{5} \mathrm{PS}$ (363.1): C, 49.57; H, 7.16; N, 3.86. Found: C, 49.54; H, 7.21; N, 3.69.

Ethoxyethyl 2-cyano-3-methylthio-3-(diethoxyphosphonyl)acrylate (2e): yellow liquid; yield 49.7\%; ${ }^{1} \mathrm{H}-\mathrm{NMR} \delta$ : 1.22 (t, $J=6.9 \mathrm{~Hz}, 3 \mathrm{H}$, ester O-C-CH ), 1.38 1.45 (m, 6H, $2 \times$ phosphonyl $\mathrm{CH}_{3}$ ), 2.75 (d, $\left.J=8.6 \mathrm{~Hz}, 3 \mathrm{H}, \mathrm{SCH}_{3}\right), 3.57$ (q, $J=6.3 \mathrm{~Hz}, 2 \mathrm{H}$, ester $\mathrm{OCH}_{2}$ ), 3.72 3.74 (m, 2H, ester $\mathrm{CH}_{2}$ ), 4.30 4.32 (m, 4H, $2 \times$ phosphonyl $\mathrm{CH}_{2}$ ), 4.39 4.41 (m, 2H, ester $\mathrm{CH}_{2}$ ); ${ }^{13} \mathrm{C}-\mathrm{NMR} \delta$ : 15.2 (ethoxy $\mathrm{CH}_{3}$ ), 16.3 (2 $\times$ phosphonyl $\left.\mathrm{CH}_{3}\right), 19.6\left(\mathrm{SCH}_{3}\right), 64.6\left(2 \times\right.$ phosphonyl $\left.\mathrm{CH}_{2}\right), 65.9\left(\right.$ ester $\left.\mathrm{OCH}_{2}\right), 66.9\left(\right.$ ethoxy $\left.\mathrm{OCH}_{2}\right)$, 67.8 (ester $\mathrm{CH}_{2} \mathrm{O}$ ), 106.0 (C=C C-2 ), $114.5(\mathrm{CN}), 162.2$ (C=C C-3), $164.9(\mathrm{C}=\mathrm{O})$; ${ }^{31} \mathrm{P}-\mathrm{NMR} \delta$ : 5.15; IR $v$ : 2953, 2992, 2852, 2214, 1714, 1444, 1249, 1120, $1012 \mathrm{~cm}^{-1}$; Anal. Calcd. for $\mathrm{C}_{13} \mathrm{H}_{22} \mathrm{NO}_{6} \mathrm{PS}$ (351.1): C, 44.43; H, 6.27; N, 3.99. Found: C, 44.44; H, 6.31; N, 3.89.

Ethoxyethyl 2-cyano-3-methylthio-3-(di-i-propoxyphosphonyl)acrylate (2f): yellow liquid; yield 57.5\%; ${ }^{1} \mathrm{H}-\mathrm{NMR} \delta: 1.22(\mathrm{t}, J=6.9 \mathrm{~Hz}, 3 \mathrm{H}$, ester O-C-CH$), 1.41 \sim 1.45\left(\mathrm{~m}, 12 \mathrm{H}, 4 \times\right.$ phosphonyl $\left.\mathrm{CH}_{3}\right), 2.72(\mathrm{~d}$, $\left.J=14.3 \mathrm{~Hz}, 3 \mathrm{H}, \mathrm{SCH}_{3}\right), 3.57\left(\mathrm{q}, J=6.9 \mathrm{~Hz}, 2 \mathrm{H}\right.$, ester $\left.\mathrm{OCH}_{2}\right), 3.72 \sim 3.73\left(\mathrm{~m}, 2 \mathrm{H}\right.$, ester $\left.\mathrm{OCH}_{2}\right)$, 4.39 4.41 (m, 2H, ester $\mathrm{CH}_{2}$ ), 4.82 4.89 (m, 2H, $2 \times$ phosphonyl $\mathrm{CH}$ ); ${ }^{13} \mathrm{C}$ - NMR $\delta$ : 15.1 (ethoxy $\mathrm{CH}_{3}$ ), $19.7\left(\mathrm{SCH}_{3}\right), 23.8$ (4 × phosphonyl $\left.\mathrm{CH}_{3}\right), 65.7$ (ester $\left.\mathrm{CH}_{2}\right), 66.7$ (ethoxy $\mathrm{OCH}_{2}$ ), 67.7 (ester $\left.\mathrm{CH}_{2} \mathrm{O}\right), 74.2(2 \times$ phosphonyl CH), $106.6(\mathrm{C}=\mathrm{C} \mathrm{C}-2), 114.5(\mathrm{CN}), 162.0(\mathrm{C}=\mathrm{C} \mathrm{C}-3), 166.8(\mathrm{C}=\mathrm{O})$; ${ }^{31} \mathrm{P}-\mathrm{NMR} \quad \delta$ : 4.76; IR $v$ : 2978, 2933, 2214, 1732, 1454, 1251, 1118, $987 \mathrm{~cm}^{-1}$; Anal. Calcd. for $\mathrm{C}_{15} \mathrm{H}_{26} \mathrm{NO}_{6} \mathrm{PS}$ (379.4): C, 47.44; H, 6.85; N, 3.69. Found: C, 47.48; H, 6.91; N, 3.51.

Ethoxyethyl 2-cyano-3-methylthio-3-(di-n-propoxyphosphonyl)acrylate (2g): yellow liquid; yield 55.6\%; ${ }^{1} \mathrm{H}-\mathrm{NMR} \delta$ : 0.98 1.00 (m, 6H, $2 \times$ phosphonyl $\mathrm{CH}_{3}$ ), 1.21 (t, $J=6.9 \mathrm{~Hz}, 3 \mathrm{H}$, ester O-C-CH ), 1.73 1.80 (m, 4H, $2 \times$ phosphonyl $\mathrm{CH}_{2}$ ), 2.75 (d, $\left.J=9.1 \mathrm{~Hz}, 3 \mathrm{H}, \mathrm{SCH}_{3}\right), 3.57$ (q, $J=7.2 \mathrm{~Hz}, 2 \mathrm{H}$, ester $\mathrm{OCH}_{2}$ ), 3.72 3.74 (m, 2H, ester $\left.\mathrm{CH}_{2}\right), 4.16 \sim 4.20$ (m, 4H, $2 \times$ phosphonyl $\left.\mathrm{CH}_{2}\right), 4.39 \sim 4.41(\mathrm{~m}, 2 \mathrm{H}$, ester $\left.\mathrm{CH}_{2}\right)$; ${ }^{13} \mathrm{C}$-NMR $\delta$ : $10.1\left(2 \times\right.$ phosphonyl $\left.\mathrm{CH}_{3}\right), 15.2$ (ethoxy $\left.\mathrm{OCH}_{3}\right), 19.6\left(\mathrm{SCH}_{3}\right), 23.7(2 \times$ phosphonyl $\mathrm{CH}_{2} \mathrm{COP}$ ), 65.9 (ester $\mathrm{OCH}_{2}$ ), 66.3 (ethoxy $\mathrm{OCH}_{2}$ ), 67.8 (ester $\mathrm{CH}_{2} \mathrm{O}$ ), $70.0(2 \times$ phosphonyl $\mathrm{CH}_{2} \mathrm{OP}$ ), 106.1 (C=C C-2), $114.5(\mathrm{CN}), 162.0$ (C=C C-3), $164.9(\mathrm{C}=\mathrm{O})$; ${ }^{31} \mathrm{P}-\mathrm{NMR} \delta: 5.43$; IR $v$ : 2968, 2897, 2214, 1745, 1456, 1381, 1238, 1116, $995 \mathrm{~cm}^{-1}$; Anal. Calcd. for $\mathrm{C}_{15} \mathrm{H}_{26} \mathrm{NO}_{6} \mathrm{PS}$ (379.4): C, 47.44; H, 6.85; N, 3.69. Found: C, 47.40; H, 6.81; N, 3.55.

Ethoxyethyl 2-cyano-3-methylthio-3-(di-n-butoxyphosphonyl)acrylate (2h): yellow liquid; yield 54.7\%; ${ }^{1} \mathrm{H}-\mathrm{NMR} \delta$ : 0.94 0.96 (m, 6H, $2 \times$ phosphonyl $\left.\mathrm{CH}_{3}\right), 1.22(\mathrm{t}, J=6.9 \mathrm{~Hz}, 3 \mathrm{H} \text {, ester O-C-CH})_{3}$, 1.42 1.44 (m, 4H, $2 \times$ phosphonyl $\left.\mathrm{CH}_{2}\right), 1.69 \sim 1.76\left(\mathrm{~m}, 4 \mathrm{H}, 2 \times\right.$ phosphonyl $\left.\mathrm{CH}_{2}\right), 2.75(\mathrm{~d}, J=$ $10.3 \mathrm{~Hz}, 3 \mathrm{H}, \mathrm{SCH}_{3}$ ), 3.57 (q, $J=7.5 \mathrm{~Hz}, 2 \mathrm{H}$, ethoxy $\mathrm{OCH}_{2}$ ), 3.72 3.74 (m, 2H, ester $\mathrm{OCH}_{2}$ ), 4.23 4.25 (m, $4 \mathrm{H}, 2 \times$ phosphonyl $\mathrm{CH}_{2}$ ), 4.39 4.41 (m, 2H, ester $\left.\mathrm{CH}_{2}\right) ;{ }^{13} \mathrm{C}-\mathrm{NMR}\left(\delta\right.$ : $13.6\left(2 \times\right.$ phosphonyl $\left.\mathrm{CH}_{3}\right)$, 15.2 (ethoxy $\left.\mathrm{OCH}_{3}\right), 18.8$ (2 $\times$ phosphonyl $\left.\mathrm{CH}_{2}\right), 19.6\left(\mathrm{SCH}_{3}\right), 32.4\left(2 \times\right.$ phosphonyl $\left.\mathrm{CH}_{2}\right), 65.9$ (ester 
$\mathrm{CH}_{2}$ ), 66.9 (ethoxy $\mathrm{OCH}_{2}$ ), 67.8 (2 × phosphonyl $\left.\mathrm{CH}_{2}\right), 68.3$ (ester $\left.\mathrm{CH}_{2} \mathrm{O}\right), 106.1(\mathrm{C}=\mathrm{C} \mathrm{C}-2), 114.5$ (CN), 162.0 (C=C C-3), 164.8 (C=O); ${ }^{31} \mathrm{P}-\mathrm{NMR} \delta$ : 5.44; IR v: 2960, 2872, 2214, 1732, 1714, 1249, $1056 \mathrm{~cm}^{-1}$; Anal. Calcd. for $\mathrm{C}_{17} \mathrm{H}_{30} \mathrm{NO}_{6} \mathrm{PS}$ (407.1): C, 50.11; H, 7.37; N, 3.44. Found: C, 50.13; H, 7.42; N, 3.26.

Methoxyethyl 2-cyano-3-methylthio-3-(diethoxyphosphonyl)acrylate (2i): yellow liquid; yield 60.1\%; ${ }^{1} \mathrm{H}-\mathrm{NMR} \delta$ : 1.36 1.45 (m, 6H, $2 \times$ phosphonyl $\mathrm{CH}_{3}$ ), 2.75 (d, $\left.J=7.5 \mathrm{~Hz}, 3 \mathrm{H}, \mathrm{SCH}_{3}\right), 3.41$ (s, 3H, methoxy $\mathrm{CH}_{3}$ ), 3.68 3.70 (m, 2H, ester $\mathrm{CH}_{2}$ ), 4.25 4.32 (m, 4H, $2 \times$ phosphonyl $\left.\mathrm{CH}_{2}\right), 4.39 \sim 4.42$ (m, $2 \mathrm{H}$, ester $\left.\mathrm{CH}_{2}\right)$; ${ }^{13} \mathrm{C}-\mathrm{NMR} \delta$ : $16.2\left(2 \times\right.$ phosphonyl $\left.\mathrm{CH}_{3}\right), 19.5\left(\mathrm{SCH}_{3}\right), 59.2$ (methoxy), $64.6(2 \times$ phosphonyl $\mathrm{CH}_{2}$ ), 65.6 (ester $\mathrm{CH}_{2}$ ), 69.8 (ester $\mathrm{CH}_{2} \mathrm{O}$ ), 105.8 (C=C C-2), $114.4(\mathrm{CN}), 161.9(\mathrm{C}=\mathrm{C}$ C-3), 165.0 (C=O); ${ }^{31}$ P-NMR $\delta$ : 5.11; IR $v$ : 2916, 2214, 1732, 1444, 1249, 1122, $1012 \mathrm{~cm}^{-1}$; Anal. Calcd. for $\mathrm{C}_{12} \mathrm{H}_{20} \mathrm{NO}_{6} \mathrm{PS}$ (337.1): C, 42.71; H, 5.93; N, 4.15. Found: C, 42.73; H, 5.98; N, 4.05.

Methoxyethyl 2-cyano-3-methylthio-3-(di-i-propoxyphosphonyl)acrylate (2j): yellow liquid; yield 58.1\%; ${ }^{1} \mathrm{H}-\mathrm{NMR} \delta$ : 1.36 1.42 (m, 12H, $4 \times$ phosphonyl $\mathrm{CH}_{3}$ ), 2.72 (d, $J=13.2 \mathrm{~Hz}, 3 \mathrm{H}, \mathrm{SCH}_{3}$ ), 3.40 (s, 3H, ester $\mathrm{OCH}_{3}$ ), 3.68 3.70 (m, 2H, ester $\mathrm{CH}_{2}$ ), 4.39 4.40 (m, 2H, ester $\left.\mathrm{OCH}_{2}\right), 4.82 \sim 4.89(\mathrm{~m}, 2 \mathrm{H}, 2$ $\times$ phosphonyl $\mathrm{CH}) ;{ }^{13} \mathrm{C}-\mathrm{NMR} \delta: 19.7\left(\mathrm{SCH}_{3}\right), 24.0\left(4 \times\right.$ phosphonyl $\left.\mathrm{CH}_{3}\right), 59.0\left(\right.$ methoxy $\left.\mathrm{OCH}_{3}\right), 65.9$ (ester $\mathrm{CH}_{2}$ ), 70.0 (ester $\left.\mathrm{CH}_{2}\right), 74.1$ (2 $\times$ phosphonyl $\left.\mathrm{CH}\right), 106.4(\mathrm{C}=\mathrm{C} \mathrm{C}-2), 114.4(\mathrm{CN}), 162.0(\mathrm{C}=\mathrm{C}$ C-3), 165.8 (C=O); ${ }^{31} \mathrm{P}-\mathrm{NMR} \delta$ : 5.10; IR v: 2981, 2933, 2214, 1747, 1454, 1249, $1000 \mathrm{~cm}^{-1}$; Anal. Calcd. for $\mathrm{C}_{14} \mathrm{H}_{24} \mathrm{NO}_{6} \mathrm{PS}$ (365.1): C, 46.01; H, 6.57; N, 3.83. Found: C, 45.92; H, 6.39; N 3.83.

Methoxyethyl 2-cyano-3-methylthio-3-(di-n-propoxyphosphonyl) acrylate (2k): yellow liquid; yield 55.3\%; ${ }^{1} \mathrm{H}-\mathrm{NMR} \delta$ : 0.98 1.00 (m, 6H, $2 \times$ phosphonyl $\left.\mathrm{CH}_{3}\right), 1.73 \sim 1.80\left(\mathrm{~m}, 4 \mathrm{H}, 2 \times\right.$ phosphonyl $\left.\mathrm{CH}_{2}\right)$, 2.75 (d, $J=7.5 \mathrm{~Hz}, 3 \mathrm{H}, \mathrm{SCH}_{3}$ ), 3.42 (s, 3H, methoxy $\mathrm{OCH}_{3}$ ), 3.69 3.70 (m, 2H, ester $\mathrm{OCH}_{2}$ ), 4.13 4.21 (m, 4H, $2 \times$ phosphonyl $\left.\mathrm{CH}_{2}\right), 4.40 \sim 4.42\left(\mathrm{~m}, 2 \mathrm{H}\right.$, ester $\left.\mathrm{CH}_{2}\right) ;{ }^{13} \mathrm{C}-\mathrm{NMR} \delta$ : $10.0(2 \times$ phosphonyl $\mathrm{CH}_{3}$ ), $19.5\left(\mathrm{SCH}_{3}\right), 23.7$ (2 $\times$ phosphonyl $\mathrm{CH}_{2}$ ), 59.2 (methoxy $\left.\mathrm{OCH}_{3}\right), 65.6$ (ester $\mathrm{CH}_{2}$ ), 69.8 (2 × phosphonyl $\left.\mathrm{CH}_{2} \mathrm{OP}\right), 69.9$ (ester $\left.\mathrm{CH}_{2}\right), 105.9$ (C=C C-2), $114.4(\mathrm{CN}), 162.1$ (C=C C-3), 165.0 (C=O); ${ }^{31} \mathrm{P}-\mathrm{NMR} \delta$ : 5.38; IR v: 2968, 2897, 2214, 1724, 1465, 1247, $1000 \mathrm{~cm}^{-1}$; Anal. Calcd. for $\mathrm{C}_{14} \mathrm{H}_{24} \mathrm{NO}_{6} \mathrm{PS}$ (365.1): C, 46.01; H, 6.57; N, 3.83. Found: C, 45.82; H, 7.42; N 3.83.

Methoxyethyl 2-cyano-3-methylthio-3-(di-n-butoxyphosphonyl)acrylate (2l): yellow liquid; yield 51.0\%; ${ }^{1} \mathrm{H}-\mathrm{NMR} \delta$ : 0.94 0.97 (m, 6H, $2 \times$ phosphonyl $\left.\mathrm{CH}_{3}\right), 1.41 \sim 1.44\left(\mathrm{~m}, 4 \mathrm{H}, 2 \times \mathrm{CH}_{2}\right), 1.69 \sim 1.76$ (m, 4H, $2 \times \mathrm{CH}_{2}-\mathrm{C}-\mathrm{O}-\mathrm{P}=\mathrm{O}$ ), 2.74 (d, $J=8.0 \mathrm{~Hz}, 3 \mathrm{H}, \mathrm{SCH}_{3}$ ), 3.41 (s, 3H, ester $\mathrm{OCH}_{3}$ ), 3.68 3.70 (m, 2H, ester $\mathrm{CH}_{2}$ ), 4.20 4.24 (m, 4H, $2 \times$ phosphonyl $\mathrm{CH}_{2}$ ), $4.40 \sim 4.42\left(\mathrm{~m}, 2 \mathrm{H}\right.$, ester $\left.\mathrm{CH}_{2}\right)$; ${ }^{13} \mathrm{C}-\mathrm{NMR} \delta$ : $13.5\left(2 \times\right.$ phosphonyl $\left.\mathrm{CH}_{3}\right), 18.6$ ( $2 \times$ phosphonyl $\left.\mathrm{CH}_{2}\right), 18.7\left(\mathrm{SCH}_{3}\right), 32.2\left(2 \times\right.$ phosphonyl $\left.\mathrm{CH}_{2}\right), 59.2$ (methoxy $\mathrm{OCH}_{3}$ ), 65.6 (ester $\left.\mathrm{CH}_{2}\right), 68.2$ (2 $\times$ phosphonyl $\left.\mathrm{CH}_{2} \mathrm{OP}\right), 69.8$ (ester $\left.\mathrm{CH}_{2}\right), 105.8(\mathrm{C}=\mathrm{C} \mathrm{C}-2)$, 114.4 (CN), 161.9 (C=C C-3), 165.0 (C=O); ${ }^{31} \mathrm{P}-\mathrm{NMR} \delta$ : 5.39; IR v: 2956, 2872, 2214, 1734, 1458, 1253, $1002 \mathrm{~cm}^{-1}$; Anal. Calcd. for $\mathrm{C}_{16} \mathrm{H}_{28} \mathrm{NO}_{6} \mathrm{PS}$ (393.1): C, 48.84; H, 7.12; N, 3.56. Found: C 48.80, H, 7.17; N, 3.43.

Ethyl 2-cyano-3-methylthio-3-[di-(2-methoxyethoxy)phosphonyl]acrylate (2m): yellow liquid; yield 60.0\%; ${ }^{1} \mathrm{H}-\mathrm{NMR} \delta: 1.36 \sim 1.38\left(\mathrm{~m}, 3 \mathrm{H}\right.$, ester $\left.\mathrm{CH}_{3}\right), 2.78\left(\mathrm{~d}, J=10.9 \mathrm{~Hz}, 3 \mathrm{H}, \mathrm{SCH}_{3}\right), 3.39(\mathrm{~s}, 6 \mathrm{H}, 2 \times$ phosphonyl $\mathrm{CH}_{3}$ ), 3.62 3.67 (m, 4H, $2 \times$ phosphonyl $\mathrm{CH}_{2}$ ), 4.31 4.40 (m, 6H, $2 \times$ phosphonyl $\mathrm{CH}_{2}+$ 
ester $\mathrm{CH}_{2}$ ); ${ }^{13} \mathrm{C}-\mathrm{NMR} \delta$ : 14.0 (ester $\mathrm{CH}_{3}$ ), $19.2\left(\mathrm{SCH}_{3}\right), 58.7$ (phosphonyl $\mathrm{OCH}_{3}$ ), 62.7 (ester $\mathrm{OCH}_{2}$ ), 66.7 ( $2 \times$ phosphonyl $\left.\mathrm{CH}_{2} \mathrm{OP}\right), 71.0\left(2 \times\right.$ phosphonyl $\left.\mathrm{CH}_{2}\right), 106.0(\mathrm{C}=\mathrm{C} \mathrm{C}-2), 114.7(\mathrm{CN}), 162.1(\mathrm{C}=\mathrm{C}$ C-3), 164.6 (C=O); ${ }^{31} \mathrm{P}-\mathrm{NMR} \delta$ : 6.16; IR $v$ : 2985, 2926, 2212, 1714, 1446, 1367, 1242, $1014 \mathrm{~cm}^{-1}$; Anal. Calcd. for $\mathrm{C}_{13} \mathrm{H}_{22} \mathrm{NO}_{7} \mathrm{PS}$ (367.1): C, 42.50; H, 5.99; N, 3.81. Found: C, 42.45; H, 6.04; N, 3.72.

Ethyl 2-cyano-3-methylthio-3-[di-(2-ethoxyethoxy)phosphonyl]acrylate (2n): yellow liquid; yield 57.6\%; ${ }^{1} \mathrm{H}-\mathrm{NMR} \delta: 1.20$ (q, 6H, $J=7.1 \mathrm{~Hz}, 2 \times$ phosphonyl $\mathrm{CH}_{3}$ ), 1.36 1.38 (m, 3H, ester $\mathrm{CH}_{3}$ ), 2.78 (d, J=10.8 Hz, 3H, $\left.\mathrm{SCH}_{3}\right), 3.52 \sim 3.55\left(\mathrm{~m}, 4 \mathrm{H}, 2 \times\right.$ phosphonyl $\left.\mathrm{CH}_{2}\right), 3.65 \sim 3.70(\mathrm{~m}, 4 \mathrm{H}, 2 \times$ phosphonyl $\mathrm{CH}_{2}$ ), 4.31 4.40 (m, 6H, 2 x phosphonyl $\mathrm{CH}_{2}+$ ester $\left.\mathrm{CH}_{2}\right) ;{ }^{13} \mathrm{C}-\mathrm{NMR} \delta$ : $15.0\left(\mathrm{SCH}_{3}\right), 66.5$ (ester $\mathrm{OCH}_{2}$ ), 66.6 (2 $\times$ phosphonyl $\left.\mathrm{CH}_{2}\right), 66.9\left(2 \times\right.$ phosphonyl $\left.\mathrm{CH}_{2}\right), 67.0\left(2 \times\right.$ phosphonyl $\left.\mathrm{CH}_{2}\right)$, 106.0 (C=C C-2), 114.7 (CN), 162.2 (C=C C-3), $165.0(\mathrm{C}=\mathrm{O}) ;{ }^{31} \mathrm{P}-\mathrm{NMR} \delta$ : 5.93; IR v: 2970, 2868, 2212, 1720, 1446, 1367, 1244, $1016 \mathrm{~cm}^{-1}$; Anal. Calcd. for $\mathrm{C}_{15} \mathrm{H}_{26} \mathrm{NO}_{7} \mathrm{PS}$ (395.1): C, 45.56; H, 6.58; N, 3.39. Found: C, 45.51; H, 6.63; N, 3.54 .

Ethoxyethyl 2-cyano-3-methylthio-3-[di-(2-methoxyethoxy)phosphoryl]acrylate (2o): yellow liquid; yield 53.5\%; ${ }^{1} \mathrm{H}-\mathrm{NMR} \delta$ : 1.21 (t, 3H, $J=6.9 \mathrm{~Hz}, \mathrm{CH}_{3}$ of ethoxy), 2.77 (d, $J_{\mathrm{PH}}=17.0 \mathrm{~Hz}, 3 \mathrm{H}, \mathrm{SCH}_{3}$ ), $3.38\left(\mathrm{~s}, 6 \mathrm{H}, 2 \times \mathrm{OCH}_{3}\right), 3.55 \sim 3.74\left(\mathrm{~m}, 8 \mathrm{H}, 2 \times \mathrm{CH}_{2} \mathrm{C}-\mathrm{O}\right.$ of phosphonyl $+\mathrm{COOCCH}_{2}$ of ester $+\mathrm{CH}_{2}$ of ethoxy), 4.24 4.41 (m, $6 \mathrm{H}, 2 \times \mathrm{CH}_{2} \mathrm{O}$ of phosphonyl $+\mathrm{COOCH}_{2}$ of ester); ${ }^{13} \mathrm{C}-\mathrm{NMR} \delta: 15.1\left(\mathrm{CH}_{3}\right.$ of ethoxy), $19.3\left(\mathrm{SCH}_{3}\right), 58.7\left(2 \times \mathrm{OCH}_{3}\right), 59.0\left(\mathrm{CH}_{2}\right.$ of ethoxy), $66.1\left(\mathrm{OCH}_{2}\right.$ of ester $), 66.8\left(2 \times \mathrm{CH}_{2} \mathrm{O}\right.$ of phosphonyl), $67.8\left(\mathrm{OCCH}_{2}\right.$ of ester), 71.1 ( $2 \times \mathrm{CH}_{2} \mathrm{C}-\mathrm{O}$ of phosphonyl), 105.7 (C-2 of $\left.\mathrm{C}=\mathrm{C}\right), 114.6$ (CN), 162.1 (C-3 of C=C), $165.0(\mathrm{C}=\mathrm{O})$; ${ }^{31} \mathrm{P}-\mathrm{NMR} \delta$ : 6.11; IR $v: 2927,2214,1747,1456,1371,1253$, $1033 \mathrm{~cm}^{-1}$; Anal. Calcd. for $\mathrm{C}_{15} \mathrm{H}_{26} \mathrm{NO}_{8} \mathrm{PS}$ (411.1): C 43.79; H 6.37; N 3.40. Found: C 43.76, H 6.43, N 3.41 .

Ethoxyethyl 2-cyano-3-methylthio-3-[di-(2-ethoxyethoxy)phosphoryl]acrylate (2p): yellow liquid; yield 56.2\%; ${ }^{1} \mathrm{H}-\mathrm{NMR} \delta: 1.21 \sim 1.39\left(\mathrm{~m}, 9 \mathrm{H}, 3 \times \mathrm{CH}_{3}\right), 2.78\left(\mathrm{~d}, J_{\mathrm{PH}}=17.1 \mathrm{~Hz}, 3 \mathrm{H}, \mathrm{SCH}_{3}\right), 3.50-3.59$ (m, $\left.6 \mathrm{H}, 3 \times \mathrm{OCH}_{2}\right), 3.63 \sim 3.73\left(\mathrm{~m}, 6 \mathrm{H}, 2 \times\right.$ phosphonyl $\mathrm{CH}_{2} \mathrm{C}-\mathrm{O}+$ ester $\left.\mathrm{COOCCH}_{2}\right), 4.27 \sim 4.41(\mathrm{~m}, 6 \mathrm{H}, 2$ $\times$ phosphonyl $\mathrm{CH}_{2} \mathrm{O}+$ ester $\left.\mathrm{COOCH}_{2}\right) ;{ }^{13} \mathrm{C}-\mathrm{NMR} \delta$ : $15.1\left(3 \times\right.$ ethoxy $\left.\mathrm{CH}_{3}\right), 19.3\left(\mathrm{SCH}_{3}\right), 66.5(3 \times$ ethoxy $\mathrm{OCH}_{2}$ ), 66.8, 67.0 (ester $\mathrm{OCH}_{2}+2 \times$ phosphonyl $\mathrm{CH}_{2} \mathrm{O}$ ), 68.9, 69.0 (ester $\mathrm{OCCH}_{2}+2 \times$ phosphonyl $\mathrm{CH}_{2} \mathrm{C}-\mathrm{O}$ ), 105.8 (C=C C-2), $114.6(\mathrm{CN}), 162.1$ (C=C C-3), $165.1(\mathrm{C}=\mathrm{O})$; ${ }^{31} \mathrm{P}-\mathrm{NMR} \delta$ : 6.30; IR v: 2974, 2214, 1747, 1583, 1485, 1253, $1035 \mathrm{~cm}^{-1}$; Anal. Calcd. for $\mathrm{C}_{17} \mathrm{H}_{30} \mathrm{NO}_{8} \mathrm{PS}$ (439.1): C 46.46; H 6.88; N 3.19. Found: C 46.60, H 6.95, N 3.26.

Methyl 2-cyano-3-methylthio-3-(diethoxyphosphonyl)acrylate (2q): yellow liquid; yield 61.0\%; ${ }^{1} \mathrm{H}$ NMR $\delta$ : 1.33 1.45 (m, 6H, $2 \times$ phosphonyl $\mathrm{CH}_{3}$ ), 2.77 (d, $\left.J_{\mathrm{PH}}=13.7 \mathrm{~Hz}, 3 \mathrm{H}, \mathrm{SCH} 3\right), 3.88$ (d, $J_{\mathrm{PH}}=7.5$ $\mathrm{Hz}, 3 \mathrm{H}, \mathrm{OCH}_{3}$ ), 4.01 4.34 (m, 4H, $2 \times$ phosphonyl $\left.\mathrm{CH}_{2}\right) ;{ }^{13} \mathrm{C}$ NMR $\delta: 16.2\left(2 \times\right.$ phosphonyl $\left.\mathrm{CH}_{3}\right)$, $19.5\left(\mathrm{SCH}_{3}\right), 53.7\left(\mathrm{OCH}_{3}\right), 64.5\left(2 \times\right.$ phosphonyl $\left.\mathrm{CH}_{2}\right), 105.5(\mathrm{C}=\mathrm{C} \mathrm{C}-2), 114.6(\mathrm{CN}), 162.6(\mathrm{C}=\mathrm{C}$ C-3), $165.3(\mathrm{C}=\mathrm{O})$; ${ }^{31} \mathrm{P}-\mathrm{NMR} \delta$ : 5.0; IR $v$ : 2983, 2214, 1749, 1255, $1037 \mathrm{~cm}^{-1}$; Anal. Calcd. for $\mathrm{C}_{10} \mathrm{H}_{16} \mathrm{NO}_{5} \mathrm{PS}$ (293.1): C 40.95, H 5.50, N 4.78. Found: C 40.91, H 5.47, N 4.81.

Methyl 2-cyano-3-methylthio-3-(di-i-propoxyphosphonyl)acrylate (2r): yellow liquid; yield 58.2\%; ${ }^{1} \mathrm{H}$ NMR $\delta$ : 1.35 1.44 (m, 12H, $4 \times$ phosphonyl $\left.\mathrm{CH}_{3}\right), 2.74$ (d, $\left.J_{\mathrm{PH}}=6.9 \mathrm{~Hz}, 3 \mathrm{H}, \mathrm{SCH}_{3}\right), 3.87$ (d, $J=8.1$ $\left.\mathrm{Hz}, 3 \mathrm{H}, \mathrm{OCH}_{3}\right), 4.83 \sim 4.89(\mathrm{~m}, 2 \mathrm{H}, 2 \times$ phosphonyl $\mathrm{CH}) ;{ }^{13} \mathrm{C}-\mathrm{NMR} \delta: 19.8\left(\mathrm{SCH}_{3}\right), 23.9(4 \times$ 
phosphonyl $\left.\mathrm{CH}_{3}\right), 53.7\left(\mathrm{OCH}_{3}\right), 74.4$ (2 $\times$ phosphonyl $\left.\mathrm{CH}\right), 106.3(\mathrm{C}=\mathrm{C} \mathrm{C}-2), 114.9(\mathrm{CN}), 162.7(\mathrm{C}=\mathrm{C}$ C-3), 166.3 (C=O); ${ }^{31} \mathrm{P}-\mathrm{NMR} \delta$ : 4.90; IR v: 2980, 2214, 1753, 1454, 1251, $999 \mathrm{~cm}^{-1}$; Anal. Calcd. for $\mathrm{C}_{12} \mathrm{H}_{20} \mathrm{NO}_{5} \mathrm{PS}$ (335.1): C 44.85, H 6.27, N 4.36. Found: C 44.77, H 6.11, N 4.40.

Methyl 2-cyano-3-methylthio-3-(di-n-propoxyphosphonyl)acrylate (2s): yellow liquid; yield 56.3\%; ${ }^{1} \mathrm{H}-\mathrm{NMR} \delta$ : 0.98 1.00 (m, 6H, $2 \times$ phosphonyl $\left.\mathrm{CH}_{3}\right), 1.72 \sim 1.80\left(\mathrm{~m}, 4 \mathrm{H}, 2 \times\right.$ phosphonyl $\left.\mathrm{CH}_{2} \mathrm{C}-\mathrm{O}\right)$, $2.76\left(\mathrm{~d}, J_{\mathrm{PH}}=4.6 \mathrm{~Hz}, 3 \mathrm{H}, \mathrm{SCH}_{3}\right), 3.87$ (d, $\left.J=10.3 \mathrm{~Hz}, 3 \mathrm{H}, \mathrm{OCH}_{3}\right), 3.99 \sim 4.21$ (m, $4 \mathrm{H}, 2 \times$ phosphonyl $\left.\mathrm{CH}_{2} \mathrm{O}\right) ;{ }^{13} \mathrm{C}-\mathrm{NMR} \delta$ : 10.1 (2 $\times$ phosphonyl $\left.\mathrm{CH}_{3}\right), 19.6\left(\mathrm{SCH}_{3}\right), 23.8\left(2 \times\right.$ phosphonyl $\left.\mathrm{CH}_{2} \mathrm{C}-\mathrm{O}\right), 53.8$ $\left(\mathrm{OCH}_{3}\right), 70.0\left(2 \times\right.$ phosphonyl $\left.\mathrm{CH}_{2} \mathrm{O}\right), 105.7$ (C=C C-2), $114.6(\mathrm{CN}), 162.5(\mathrm{C}=\mathrm{C} \mathrm{C}-3), 165.4(\mathrm{C}=\mathrm{O})$; ${ }^{31} \mathrm{P}-\mathrm{NMR} \delta$ : 5.3; IR v: 2968, 2214, 1751, 1462, 1253, $1002 \mathrm{~cm}^{-1}$; Anal. Calcd. for $\mathrm{C}_{12} \mathrm{H}_{20} \mathrm{NO}_{5} \mathrm{PS}$ (321.3): C 44.85, H 6.27, N 4.36. Found: C 45.01, H 6.18, N 4.38.

Methyl 2-cyano-3-methylthio-3-(di-n-butoxyphosphonyl)acrylate (2t): yellow liquid; yield 57.3\%; ${ }^{1} \mathrm{H}-\mathrm{NMR} \delta$ : 0.94 0.98 (m, 6H, $2 \times$ phosphonyl $\left.\mathrm{CH}_{3}\right), 1.38-1.47$ (m, 4H, $2 \times$ phosphonyl $\left.\mathrm{CH}_{2} \mathrm{CCO}\right)$, 1.65-1.77 (m, 4H, $2 \times$ phosphonyl $\mathrm{CH}_{2} \mathrm{CO}$ ), 2.75 (d, $\left.J_{\mathrm{PH}}=4.6 \mathrm{~Hz}, 3 \mathrm{H}, \mathrm{SCH}_{3}\right), 3.87$ (d, $J=10.3 \mathrm{~Hz}, 3 \mathrm{H}$, $\left.\mathrm{OCH}_{3}\right), 4.08 \sim 4.25\left(\mathrm{~m}, 2 \mathrm{H}, 4 \mathrm{H}, 2 \times\right.$ phosphonyl $\left.\mathrm{CH}_{2} \mathrm{O}\right) ;{ }^{13} \mathrm{C}-\mathrm{NMR} \delta$ : 13.6 (2 $\times$ phosphonyl $\left.\mathrm{CH}_{3}\right), 18.7$ (2 $\times$ phosphonyl $\left.\mathrm{CH}_{2} \mathrm{CCO}\right), 18.8\left(\mathrm{SCH}_{3}\right), 32.2\left(2 \times\right.$ phosphonyl $\left.\mathrm{CH}_{2} \mathrm{C}-\mathrm{O}\right), 53.8\left(\mathrm{OCH}_{3}\right), 68.2(2 \times$ phosphonyl $\mathrm{CH}_{2} \mathrm{O}$ ), $105.6(\mathrm{C}=\mathrm{C} \mathrm{C}-2), 114.6(\mathrm{CN}), 162.6(\mathrm{C}=\mathrm{C} \mathrm{C}-3), 165.3(\mathrm{C}=\mathrm{O})$; ${ }^{31} \mathrm{P}-\mathrm{NMR} \delta$ : 5.3; IR v: 2960, 2214, 1743, 1462, 1255, $1020 \mathrm{~cm}^{-1}$; Anal. Calcd. for $\mathrm{C}_{14} \mathrm{H}_{24} \mathrm{NO}_{5} \mathrm{PS}$ (349.1): C 48.13, $\mathrm{H}$ 6.92, N 4.01. Found: C 48.46, H 7.04, N 3.91.

\section{Antifungal bioassay}

The antifungal activity of all synthesized compounds were tested against three pathogenic fungi. namely Fusarium graminearum, Cytospora mandshurica and Fusarium oxysporum, by the poison plate technique [16]. Compounds were dissolved in DMSO (1 mL) before mixing with potato dextrose agar (PDA, $90 \mathrm{~mL}$ ). The final concentration of compounds in the medium were fixed at 50 and 500 $\mu \mathrm{g} / \mathrm{mL}$. All types of fungi were incubated in PDA at $25 \pm 1{ }^{\circ} \mathrm{C}$ for 4 days to get new mycelium for the antifungal assays, then a mycelia disk of approximately $4 \mathrm{~mm}$ diameter cut from culture medium was picked up with a sterilized inoculation needle and inoculated in the center of the PDA plate. The inoculated plates were incubated at $25 \pm 1{ }^{\circ} \mathrm{C}$ for 5 days. DMSO in sterile distilled water served as control, while hymexazole severed as positive control. For each treatment, three replicates were conducted. The radial growth of the fungal colonies were measured and the data were statistically analyzed. The inhibitory effects of the test compounds on these fungi in vitro were calculated by the formula $I=(\mathrm{C}-\mathrm{T} / \mathrm{C}) \times 100$, where $\mathrm{C}$ represents the diameter of fungi growth on untreated PDA, and $\mathrm{T}$ represents the diameter of fungi on treated PDA while $I$ represents the inhibition rate.

\section{Hyphal morphology of F. oxysporum}

Compound 2d (final conc. $100 \mu \mathrm{g} / \mathrm{mL}$ ) was added to sterilized Czapek media $\left(0.2 \% \mathrm{NaNO}_{3}, 0.131\right.$ $\% \mathrm{~K}_{2} \mathrm{HPO}_{4} \cdot 3 \mathrm{H}_{2} \mathrm{O}, 0.05 \% \mathrm{KCl}, 0.05 \% \mathrm{MgSO}_{4} \cdot 7 \mathrm{H}_{2} \mathrm{O}, 0.00183 \% \mathrm{FeSO}_{4} \cdot 7 \mathrm{H}_{2} \mathrm{O}, 3 \%$ sucrose, pH 6.8) [17] in which F. oxysporum had incubated for a few days. After incubating together at $27{ }^{\circ} \mathrm{C}$ for $24 \mathrm{~h}$, it was observed under microscope (Olympus $800 \times$ ). Acetone $(0.5 \mathrm{~mL})$ served as the control. 
Antiviral Biological Assays

Purification of tobacco mosaic virus: Using Gooding's method [18], the upper leaves of Nicotiana tabacum $L$ inoculated with TMV were selected and were ground in phosphate buffer, then filtered through double layer pledget. The filtrate was centrifuged at 10,000 g, treated twice with PEG and centrifuged again. The whole experiment was carried out at $4{ }^{\circ} \mathrm{C}$. Absorbance values were estimated at $260 \mathrm{~nm}$ using an ultraviolet spectrophotometer. Virus concn $=\left(A_{260} \times\right.$ dilution ratio $) / E^{0.1 \%}$

Protective effects of compounds on TMV in vivo: The compound solution was smeared on the left side while solvent was served as control on the right side of growing Nicotiana tabacum. $L$ leaves of the same ages. The leaves were then inoculated with the virus after 12 hours. A brush was dipped in tobacco mosaic virus of $6 \times 10^{-3} \mathrm{mg} / \mathrm{mL}$ to inoculate the leaves, which were previously scattered with silicon carbide. The leaves were then washed with water and rubbed softly along the nervature once or twice. The local lesion numbers appearing 3-4 days after inoculation were counted [7]. Three repetitions were conducted for each compound.

Inactivation effect of compounds on TMV in vivo: The virus was inhibited by mixing with the compound solution at the same volume for 30 minutes. The mixture was then inoculated on the left side of the leaves of Nicotiana tabacum. L., while the right side of the leaves was inoculated with the mixture of solvent and the virus for control. The local lesion numbers were recorded 3-4 days after inoculation [7]. Three repetitions were conducted for each compound.

Curative effect of compounds on TMV in vivo: Growing leaves of Nicotiana tabacum. $L$ of the same ages were selected. The tobacco mosaic virus (concentration of $6 \times 10^{-3} \mathrm{mg} / \mathrm{mL}$ ) was dipped and inoculated on the whole leaves. Then the leaves were washed with water and dried. The compound solution was smeared on the left side and the solvent was smeared on the right side for control. The local lesion numbers were then recorded 3-4 days after inoculation [7]. For each compound, three repetitions were conducted to ensure the reliability of the results, which were measured according to the following formula:

Inhibition rate $(\%)=$ av local lesion numbers of control (not treated with compound) - av local lesion numbers smeared with drugs av local lesion numbers without drugs

\section{References}

1. Mackay, S. P.; O’Malley, P. J. Z. Molecular modelling of the interaction between DCMU and the Q(B)-binding site of photosystem-II. Z. Naturforsch. 1993, 48c, 191-198.

2. Huppatz, J. L.; Phillips, J. N.; Rattigan B. M. Cyanoacrylates. Herbicidal and photosynthetic inhibitory activity. Agric. Biol. Chem. 1981, 45, 2769-2773.

3. Wang, Q. M.; Li, H.; Li, Y. H., Huang, R. Q. Synthesis and herbicidal activity of 2-cyano-3(2-chlorothiazol-5-yl)methylaminoacrylates. J. Agric. Food Chem. 2004, 52, 1918-1922.

4. Wang, L. G.; Wang, F. Y.; Diao, Y. M.; Ni, Y. P.; Wei, P. Synthesis and fungicidal activity of ethyl 2-cyano-3-substituted-amino-3-(2-methylphenyl)propenoate. Chin. J. Org. Chem. 2005, 25, 1254-1258. 
5. Song, B. A.; Yang, S.; Zhong, H. M.; Jin, L. H.; Hu, D. Y.; Liu, G. Synthesis and bioactivity of 2-cyanoacrylates containing a trifluoromethylphenyl moiety. J. Fluorine Chem. 2005, 126, 87-92.

6. Zhang, H. P.; Song, B. A.; Zhong, H. M.; Yang, S.; Jin, L. H.; Hu, D. Y.; He, W. Synthesis of 2-cyanoacrylates containing pyridinyl moiety under ultrasound irradiation. J. Heterocyclic Chem., 2005, 42, 1211-1214.

7. Song, B. A.; Zhang, H. P.; Wang, H.; Yang, S.; Jin, L. H.; Hu, D. Y.; Pang, L. L.; Xue, W. Synthesis and antiviral activity of novel chiral cyanoacrylate derivatives. J. Agric. Food Chem. 2005, 53, 7886-7891.

8. Boehner, B.; Hall, R. G. Preparation of pyrazolylphosphonate pestcides. DE 4139849, 1992. [Chem. Abstr. 1992, 117, 131386n].

9. Cross, H.; Koeckritz, A.; Scheidecker, S.; Schnell, M. Preparation of dialkyl 5-aminooxazole-5phosphonates. DE 4108345, 1992 [Chem. Abstr 1992, 117, 251560 m].

10. Fouque, D.; About-Jaudet, E.; Collignon, N. Alpha-pyrazolyl-alkylphosphonates. Part II: a simple and efficient synthesis of diethyl-1-(pyrazol-4-yl)-alkyl phosphonates. Synth. Commun. 1995, 25, 3443-3455.

11. Huang, W. S.; Yuan, C.Y. Studies on organophosphorus compounds 92: a facile synthesis of 1-substituted-5-trifluoromethylimidazole-4-phosphonates. Synthesis 1996, 4, 511-513.

12. a) Lu, R. J.; Yang, H. Z.; A novel approach to phosphonyl-substituted heterocyclic system (I). Tetrahedron Lett. 1997, 8, 5201-5204; b) Chen, K.; Hu, F. Z.; Zhang, J. H.; Wu, C. Yang, H. Z. Progress in the synthetic methods of phosphonyl heterocyclic compouds, Chin. J. Org. Chem. 2000, 20, 866-873.

13. Chen, K.; Yang, H. Z.; Liu, Z.; Hu, F. Z.; Zhang, C. X. Synthesis of Novel Phosphonyl/ S-methyl Ketene Thioacetals and N-Substituted Phosphonyl/S-methyl Thiocarbonates under Microwave Irradiation. Chin. J. Org. Chem. 2001, 21, 690-692.

14. McCombie, H.; Sauders, B. C.; Stacey, G. J. Esters containing phosphorus Part I. J. Chem. Soc. 1945, 380-382.

15. Liu, H.-Y.; Sha, Y.-L.; Dai, G. - X.; Tan, H. -F.; Yang, H.-Z.; Lai, L.-H. J. Synthesis of novel derivatives of 2-cyano-3-methylthio-3'-benzylamino-acrylates (acryl, amides) and their biological activity. Phosphorus, Sulfur Silicon 1999, 148, 235-241.

16. Erwin, D. C.; Sims, J. J.; Borum, D. E; Childers, J. R. Detection of the systemic fungicide, thiabendazole, in cotton plants and soil by chemical analysis and bioassay. Phytopathology 1971, 61, 964-967.

17. Yang, S.; Gao, X. W.; Diao, C. L.; Song, B. A.; Jin, L. H.; Xu, G. F.; Zhang, G. P.; Wang, W.; Hu, D. Y.; Xue, W.; Zhou, X.; Lu, P. Synthesis and antifungal activity of novel chiral $\alpha$-aminophosphonates containing fluorine moiety. Chin. J. Chem. 2006, 24, 1581-1588.

18. Gooding, G. V. Jr.; Hebert, T. T. A simple technique for purification of tobacco mosaic virus in large quantities. Phytopathology 1967, 57, 1285-1290.

Sample Availability: Samples of the compounds are available from authors.

(C) 2007 by MDPI (http://www.mdpi.org). Reproduction is permitted for noncommercial purposes. 